\title{
Transfection of Culicoides sonorensis biting midge cell lines with Wolbachia pipientis
}

\author{
Arnab Ghosh', Dane Jasperson ${ }^{2}$, Lee W. Cohnstaedt ${ }^{2}$ and Corey L. Brelsfoard ${ }^{1 *}$
}

\begin{abstract}
Background: Biting midges of the genus Culicoides vector multiple veterinary pathogens and are difficult to control. Endosymbionts particularly Wolbachia pipientis may offer an alternative to control populations of Culicoides and/or impact disease transmission in the form of population suppression or replacement strategies.

Methods: Culicoides sonorensis cell lines were transfected with a Wolbachia infection using a modified shell vial technique. Infections were confirmed using PCR and cell localization using fluorescent in situ hybridization (FISH). The stability of Wolbachia infections and density was determined by qPCR. QPCR was also used to examine immune genes in the IMD, Toll and JACK/STAT pathways to determine if Wolbachia were associated with an immune response in infected cells.

Results: Here we have transfected two Culicoides sonorensis cell lines (W3 and W8) with a Wolbachia infection (walbB) from donor Aedes albopictus Aa23 cells. PCR and FISH showed the presence of Wolbachia infections in both C. sonorensis cell lines. Infection densities were higher in the W8 cell lines when compared to W3. In stably infected cells, genes in the immune Toll, IMD and JAK/STAT pathways were upregulated, along with Attacin and an Attacin-like antimicrobial peptides.

Conclusions: The successful introduction of Wolbachia infections in C. sonorensis cell lines and the upregulation of immune genes, suggest the utility of using Wolbachia for a population replacement and/or population suppression approach to limit the transmission of $C$. sonorensis vectored diseases. Results support the further investigation of Wolbachia induced pathogen inhibitory effects in Wolbachia-infected C. sonorensis cell lines and the introduction of Wolbachia into C. sonorensis adults via embryonic microinjection to examine for reproductive phenotypes and host fitness effects of a novel Wolbachia infection.
\end{abstract}

Keywords: Culicoides sonorensis, Wolbachia pipientis, Population replacement, Population suppression, Biting midge

\section{Background}

Culicoides species are small hematophagous insects that have been shown to harbor more than 50 different viruses of veterinary and medical importance [1]. These viruses include orbiviruses, such as African horse sickness virus (AHSV), Schmallenberg virus (SBV), bluetongue virus (BTV) and epizootic hemorrhagic disease virus (EHDV), which significantly impact deer and livestock production through loss of profits and trade restrictions [1, 2]. Multiple outbreaks of blue tongue virus (BTV) of different

\footnotetext{
*Correspondence: corey.brelsfoard@ttu.edu

${ }^{1}$ Department of Biological Sciences, Texas Tech University, 2901 Main St., Lubbock, TX 79409, USA

Full list of author information is available at the end of the article
}

serotypes, topotypes (regional variants of particular serotypes) and strains have been recorded in Europe in recent decades [3, 4]. One of the largest European outbreaks to date recorded in the Netherlands, resulted in economic damage greater than $\$ 150$ million dollars [5]. The circulation of established and newly established BTV serotypes still continues to affect large areas of southern and eastern Europe. Currently, there are at least 11 invasive BTV serotypes circulating in the USA [6-10] and the number of serotypes in the USA is on the rise, suggesting the epidemiology of BTV is changing and could result in extensive disease in USA livestock if the virus were to infect naive host populations [11]. Worldwide estimates 
of direct and indirect losses due to BTV have been estimated to top $\$ 3$ billion dollars [12].

Culicoides-vectored arborvirus and zoonotic diseases have limited methods of treatment and prevention and rely on inadequate forms of vector control to combat the spread of the disease $[2,13,14]$. Current control methods for Culicoides are focused on treating livestock with topical insecticides at livestock production facilities and farms, but are typically met with limited success, depending on the Culicoides species targeted [2, 13, 14]. Furthermore, little is known about the biology of many Culicoides species, specifically immature habitat selection, making the effective application of insecticides to control immatures difficult $[13,15]$. Habitat modification to remove standing water and removal of manure is often used to impact populations of Culicoides near livestock, but is limited to use in areas near livestock production. The combination of larvicide and adulticidal treatments have also demonstrated some success, but the true efficiency of this type of control has not been assessed, and this type of treatment typically does not reduce the numbers of Culicoides adults, if only treating around a farm property $[16,17]$. Vaccines are available for a few Culicoides-transmitted viruses. Active virus vaccines are available for BTV serotypes, but are limited in effectiveness due to the large number of serotypes and the potential for genome segment re-assortment of the BTV [18]. Inactivated vaccines are currently available for -BTV and have been used in Europe. However, inactivated vaccines are expensive and not an effective solution when treating large amounts of livestock $[19,20]$. Therefore, alternative control measures are needed to supplement the few existing control measures for Culicoides species.

Wolbachia pipientis may offer an alternative environmentally friendly control measure for Culicoides midges and the pathogens they vector. Wolbachia is an obligate intracellular bacterium found in $>55 \%$ of insects, as well as filarial nematodes and terrestrial crustaceans $[21,22]$. In insects, Wolbachia causes alterations in host reproduction, with several phenotypes including feminization, parthenogenesis, male killing and cytoplasmic incompatibility (CI) [23]. Recently, Wolbachia has been used as a strategy for mosquito suppression and disease control and has become a topic of global relevance [24, 25]. Two Wolbachia-based strategies are currently being implemented in the field for mosquito and disease control. The first is a Wolbachia incompatible insect technique (IIT) approach based on mass inundative releases of incompatible male mosquitoes similar to the Sterile Insect Technique (SIT), with the goal of suppressing natural populations through sterile mattings [26, 27]. The second is based on the discovery that some $\mathrm{Wol}$ bachia interfere with viruses and other microbes in the same host [28-32]. Particular Wolbachia variants (e.g. the $w$ Mel strain) can block dengue virus transmission without impacting Aedes aegypti fitness [28]. In addition, Wolbachia has also been shown to impact chikungunya virus, Zika virus and the yellow fever virus in their mosquito host [28-32]. Because Wolbachia-infected females can mate and produce viable offspring with infected and uninfected males alike, and infected males when mated with uninfected female produce non-viable offspring, the resulting reproductive advantage of Wolbachia infected individuals can drive a given disease refractory phenotype into a natural population limiting disease transmission.

Biological control using Wolbachia has been limited to disease vector mosquitoes, presumably because of the immediate need for novel tools for hard to control mosquito species such as Ae. aegypti and Aedes albopictus, that are primary and secondary vectors of dengue and Zika viruses, respectively. The success of the recent field applications of Wolbachia control techniques in mosquitoes suggests the potential for the transition of this technology to other insect disease vectors of human and zoological importance. Wolbachia infections have recently been confirmed in multiple populations and species of Culicoides midges in Europe and Australia [33, 34], suggesting that introducing novel Wolbachia infection types into uninfected Culicoides species is possible. Furthermore, the existence of natural infections suggests that reproductive phenotypes such as cytoplasmic incompatibility could exist in natural populations that harbor Wolbachia infections. Here, we demonstrate that Wolbachia infections can be introduced into Culicoides sonorensis cell lines as an initial step towards the investigation of a Wolbachia based control strategy for Culicoides midges. Recent studies have suggested that Wolbachia infections from a donor host can be pre-adapted to a target host cell lines in order to facilitate the adaptation for survival in a novel host [35]. The successful transfection of Wolbachia in Culicoides sonorensis cell culture may be a precursor to the successful germ line transfection of $C$. sonorensis. Furthermore, we use transfected cell lines to investigate a host immune response associated with a Wolbachia infection, which could suggest a reduced ability of Wolbachia infected C. sonorensis to transmit viral pathogens.

\section{Methods}

\section{Cell culture}

Aa23 Ae. albopictus cell lines were cultured in $75 \mathrm{~cm}^{2}$ cell culture flasks $\left(\mathrm{TPP}^{\mathrm{TM}}\right.$, Techno Plastic Products, Trasadingen, Switzerland) in Schneider's insect medium (SM) (MilliporeSigma, St. Louis, MO, USA) supplemented with $10 \%$ fetal bovine serum (FBS) (Table 1) [36]. W8 and W3 C. sonorensis cells were cultured in $25 \mathrm{~cm}^{2}$ cell 
Table 1 Mosquito and midge cell lines used in the transfection experiments

\begin{tabular}{lllll}
\hline Cell line & Host & Natural infection status & $\begin{array}{l}\text { Transfected Wolbachia } \\
\text { type }\end{array}$ & Reference \\
\hline Aa23 & Aedes albopictus & walbB & N/A & Dobson et al. [36] \\
W8-(CuVa-W8a) & Culicoides sonorensis & Uninfected & walbB & McHolland \& Mecham [38] \\
W3-(CuVa-W3) & Culicoides sonorensis & Uninfected & walbB & McHolland \& Mecham [38] \\
\hline
\end{tabular}

culture flasks $\left(\mathrm{TPP}^{\mathrm{TM}}\right.$, Techno Plastic Products) in SM (24.5 g/l) supplemented with $0.4 \mathrm{~g} / \mathrm{l}$ sodium bicarbonate, $0.0585 \mathrm{~g} / \mathrm{l} \mathrm{L}$-glutatmine, $0.006 \mathrm{~g} / \mathrm{l}$ reduced glutathione, $0.03 \mathrm{~g} / \mathrm{l} \mathrm{L}$-Asparagine, $18 \mu \mathrm{l}$ of $10 \mathrm{mg} / \mathrm{l}$ Bovine insulin and $5 \%$ FBS (Table 1). All cell cultures were incubated at $28^{\circ} \mathrm{C}$ with a $\mathrm{CO}_{2}$ concentration of $0.2 \%$.

\section{Wolbachia isolation and transfection experiments}

The $w a l b B$ infection was isolated from the Aa23 cells grown to $>95 \%$ confluency. Extracellular Wolbachia was isolated using a modified procedure as previously described [37]. The adherent cells were scraped, and the cell culture was centrifuged at $2500 \times g$ at $4{ }^{\circ} \mathrm{C}$ for 10 min. The supernatant was removed, and the pellet was re-suspended in 6-8 $\mathrm{ml}$ of a $\mathrm{SM}+10 \%$ FBS solution. Next, $3 \mathrm{~mm}$ glass beads were added to the solution up to the three ml mark in a $15-\mathrm{ml}$ centrifuge tube and vortexed at high speed for $5 \mathrm{~min}$, followed by centrifugation at $2500 \times g$ at $4{ }^{\circ} \mathrm{C}$ for $10 \mathrm{~min}$. The supernatant was then passed through a $5-\mu \mathrm{m}$ syringe filter and the resulting solution was split into $1.5 \mathrm{ml}$ centrifuge tubes (approximately $1 \mathrm{ml}$ per tube) and subjected to sucrose gradient centrifugation (200 $\mathrm{mM}$ sucrose solution) at $17,000 \times g$ for $10 \mathrm{~min}$ at $4{ }^{\circ} \mathrm{C}$. The resulting pellet was re-suspended in SM with $10 \%$ FBS and passed through a $2.7-\mu \mathrm{m}$ syringe filter to collect extracellular Wolbachia. To examine for contamination of extracts with Aa23 cells, environmental bacteria, and/or fungi, a portion of the extract was added to Schneider's media with $10 \%$ FBS in a $25-\mathrm{cm}^{2}$ flask and incubated at $28{ }^{\circ} \mathrm{C}$ with a $\mathrm{CO}_{2}$ concentration of $0.2 \%$.

Infection of W8 and W3 cell lines was carried out using a modified shell vial technique [36]. Briefly, shell vials $(29 \times 80 \mathrm{~mm})$ were seeded with W8 or W3 cells at $90 \%$ confluency and allowed to adhere to vial surface for two hours. Isolated extracellular Wolbachia was applied to W8 or W3 cells. The shell vial was centrifuged at $2500 \times$ $g$ for $40 \mathrm{~min}$ at $20^{\circ} \mathrm{C}$ and the cells transferred to a $25-\mathrm{cm}^{2}$ flask with $5 \mathrm{ml}$ of fresh media. In an attempt to increase Wolbachia infection rates, a second shell vial experiment was performed on the previously transfected W8- $w$ and W3- $w$ cells $(2 \times)$ (Fig. 1a). One day after infection, the cells were transferred into a $25-\mathrm{cm}^{2}$ flask containing $5 \mathrm{ml}$ of fresh medium. W3- $w$ and W8- $w$ cells were passaged every 6-8 days at a ratio of 1:4 (cell culture: new media).

\section{PCR testing of Wolbachia infections}

To confirm the Wolbachia infection was successfully isolated from the Aa23 cells in passage 1 and to confirm establishment in W3- $w$ and W8- $w$ cell lines, DNA was isolated from passage 1, 6 and 14 of $2 \times$ Wolbachia infected W3-w, W8-w and uninfected W3 and W8 and Aa23 cells using a Qiagen DNeasy Blood and Tissue Kit (Qiagen, Hilden, Germany). For detection of Wolbachia, a PCR assay that amplified a 438 bp $16 S$ rRNA gene fragment was used with the specific primer set wspecF and wspecR [38] (Additional file 1: Table S1). For all RXNs, $1 \mu \mathrm{l}$ of isolated DNA was amplified in $25 \mathrm{mM} \mathrm{KCL}, 25$ $\mathrm{mM}$ Tris-HCL (pH 9.0), $20 \mathrm{mM}\left(\mathrm{NH}_{4}\right)_{2} \mathrm{SO}_{4}$, and $0.025 \%$ Triton X-100, $0.25 \mathrm{mM} \mathrm{MgCl}_{2}, 0.25 \mathrm{mM}$ dNTPs, $0.5 \mathrm{mM}$ primers, and $1 \mathrm{U}$ of Taq DNA polymerase in a total volume of $25 \mu \mathrm{l}$. The PCR amplification protocol was $10 \mathrm{~min}$ at $95{ }^{\circ} \mathrm{C}, 35$ cycles of $30 \mathrm{~s}$ at $95{ }^{\circ} \mathrm{C}, 30 \mathrm{~s}$ at $54{ }^{\circ} \mathrm{C}$ and 1 min at $72{ }^{\circ} \mathrm{C}$, followed by a $10 \mathrm{~min}$ extension step at 72 ${ }^{\circ} \mathrm{C}$ using a T100 Thermocycler (Bio-Rad, Hercules, CA, USA). A volume of 5-10 $\mu \mathrm{l}$ of each amplicon was separated on $1.5 \%$ agarose gel, stained with GelRed (Biotium, Hayward, CA, USA) and visualized under ultraviolet illumination.

\section{Fluorescence in situ hybridization}

Fluorescence in situ hybridization (FISH) was performed on the W8- $w$ and W3- $w$ and W8 and W3 cell lines to confirm the presence and absence of Wolbachia, respectively. For the FISH procedures, W8- $w$ and W3-w cells were at passage 4 post-Wolbachia infection. Cells were grown to $90 \%$ confluency at $28{ }^{\circ} \mathrm{C}$ and $300 \mu$ l of the cells were added to an 8-well Nunc ${ }^{\circledR}$ Lab-Tek ${ }^{\circledR}$ Chamber slide system (Thermo Fisher Scientific, Waltham, MA, USA). The cells were incubated in the chambered wells overnight for $\sim 15 \mathrm{~h}$ at $28^{\circ} \mathrm{C}$. Cells were fixed in $4 \%$ formaldehyde (in $1 \times \mathrm{PBS}$ ) for $40 \mathrm{~min}$ at room temperature (RT) and followed by two washes with $1 \times$ PBS-T. Next, the cells were pre-hybridized for $\sim 2 \mathrm{~h}$ at RT. The prehybridization buffer consisted of $50 \%$ deionized formamide, $20 \% 20 \times$ sodium saline citrate (SSC) solution, $1 \% 50 \times$ Denhardt's Reagent, 10\% $1 \mathrm{~mol}$ dithriothreitol (DTT), $0.25 \mathrm{mg} / \mathrm{ml} \mathrm{t}$-RNA and $0.25 \mathrm{mg} / \mathrm{ml}$ poly(A). The pre-hybridization step was followed by an overnight 


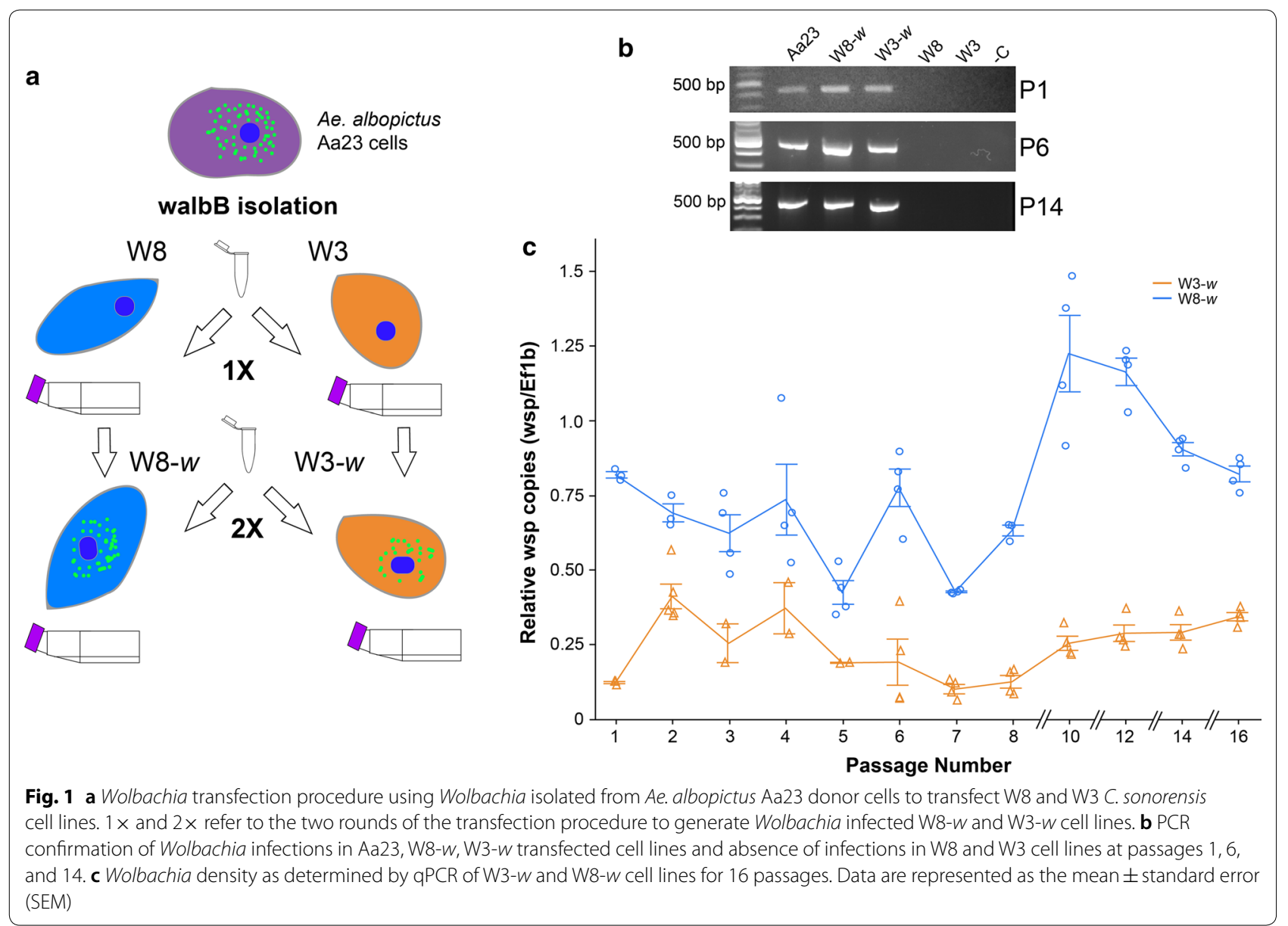

hybridization $(\sim 18 \mathrm{~h})$ at $37^{\circ} \mathrm{C}$ in a moist environment with gentle shaking. The hybridization buffer consisted of pre-hybridization buffer supplemented with $200 \mathrm{mg} /$ ml dextran sulfate, $250 \mathrm{mg} / \mathrm{l}$ salmon sperm DNA and Wolbachia specific probes (5'-/56-FAM/ AAT CCG GCC GAR CCG ACC C-3'); 5'-/56-FAM/ CTT CTG TGA GTA CCG TCA TTA TC-3') [37]. After hybridization, the cells were washed with denatured SSC solution in the following order: wash buffer $1(1 \times$ SSC augmented with $10 \mathrm{mmol} / \mathrm{l} \mathrm{DTT}$ ) at room temperature with gentle shaking, wash buffer 1 at $55^{\circ} \mathrm{C}$ with gentle shaking, and two washes at $55^{\circ} \mathrm{C}$ with wash buffer 2 $(0.5 \times$ SSC augmented with $10 \mathrm{mmol} / \mathrm{l} \mathrm{DTT})$ with gentle shaking. Following the wash steps, cells were stained with DAPI at room temperature for $5 \mathrm{~min}$ followed by three 5 -min washes with $1 \times$ PBS. The cells were then observed using a Nikon (Melville, NY, USA) A1 HD25/ A1R HD25 confocal microscope with high-definition resonant scanner at a magnification of $20 \times$ and $60 \times$. All images were processed using Image J and Adobe Photoshop (Adobe Systems, San Jose, CA, USA).

\section{Wolbachia quantification}

qPCR was used to quantify the density of Wolbachia in W8- $w$ and W3- $w$ infected cell lines. DNA was extracted from Wolbachia infected cells using Qiagen DNeasy Kit. Wolbachia density was determined by amplifying a fragment of the Wolbachia wsp gene (Additional file 1: Table S1) [39-42] using Platinum SYBR Green qPCR SuperMix-UDG (Thermo Fisher Scientific) on a Applied Biosystems 7300 real time PCR system (Applied Biosystems, Beverly, MA, USA) and completed in duplicate or triplicate. The relative abundance of Wolbachia in W8-w and W3- $w$ cell lines were normalized to the single copy elongation factor $1 \mathrm{~b}$ gene (Additional file 1: Table S1).

\section{Immune response experiments}

Qiagen RNeasy Mini Kit was used to isolate RNA for quantification of host cell gene expression (Qiagen). Isolated RNA from W8- $w$ cells was treated with DNase and cDNA synthesized using an NEVB LunaScript RT superMix kit (New England Biolabs, Ipswich, MA, USA) following the manufacturer's guidelines. To determine the 
response of the immune pathways to the walbB infection in W8- $w$ cell lines, qPCR was used to determine host gene expression of immune genes involved in the IMD, Toll and Jak/Stat pathways and anti-microbial peptides previously identified in C. sonorensis (Additional file 1: Table S1). All reactions were performed by amplifying the target immune genes using Platinum SYBR Green qPCR SuperMix-UDG, completed in triplicate and normalized to the elongation factor $1 b$ gene using the $2^{-\Delta \Delta c t}$ method.

\section{Statistics}

JMP software (SAS, Cary, NC, USA) was used for statistical analysis. Statistical significance of immune gene expression levels of Wolbachia infected and uninfected Culicoides cells was determined by t-tests, with a significance level of $P<0.05$.

\section{Results}

Establishment and Wolbachia density in Culicoides cells Prior to Wolbachia transfection procedures, W8 and W3 cell lines were confirmed for absence of a natural Wolbachia infection (Fig. 1a, b). Successful Wolbachia isolation from Aa23 cells was confirmed by a positive PCR in passage one post transfection (Fig. 1b). After two Wolbachia transfection procedures, W8- $w$ and W3- $w$ cell lines tested positive for Wolbachia infections using PCR at passages 4 and 16 (Fig. 1b). No contamination was observed in W8- $w$ and W3- $w$ cell lines post-transfection or in control flasks containing Wolbachia extract and cell culture media.

To investigate the infection dynamics of W8- $w$ and W3- $w$ cell lines, qPCR was used to determine Wolbachia density using isolated DNA samples from eight passages of W3-w and W8-w cell lines. W8- $w$ consistently maintained a higher density Wolbachia infection than W3-w (Fig. 1c), but there was no evidence for Wolbachia infection loss in either cell lines, and infections appeared to be maintained at a relative density of approximately $0.77 \pm 0.26$ (mean \pm standard deviation, SD) and $0.24 \pm 0.12$ (mean \pm SD) for the W8- $w$ and W3- $w$ cell lines, respectively (Fig. 1c). After transfection with walbB, W8- $w$ and W3- $w$ cells were able to be cryogenically frozen in SM with 10\% FBS and 10\% DMSO. Cells were able to be re-established and harbor similar densities of Wolbachia infections compared to unfrozen original cell lines for both W3 and W8 cell lines.

\section{Localization of walbB in Culicoides cells by FISH}

Wolbachia specific fluorescently labeled oligonucleotides were used to target the Wolbachia wsp gene in the Culicoides cells. No fluorescent signal was observed in the uninfected Culicoides sonorensis (Fig. 2). Fluorescent microscopy observations showed the presence of Wolbachia in the cytoplasm of the W8-w and W3-w cell lines. However, the limited level of hybridization suggested a
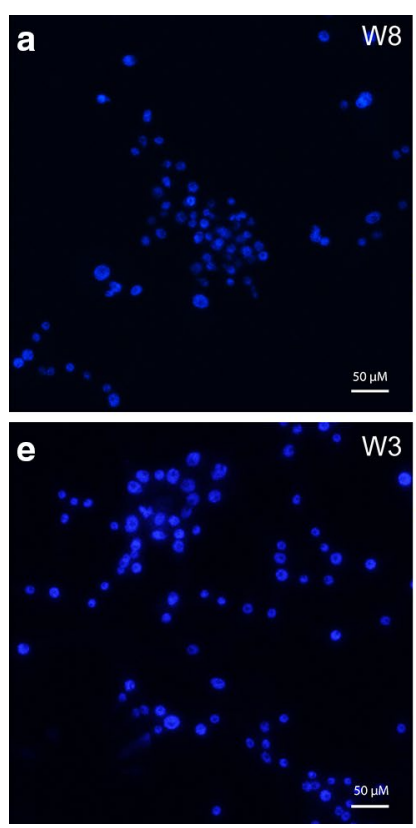
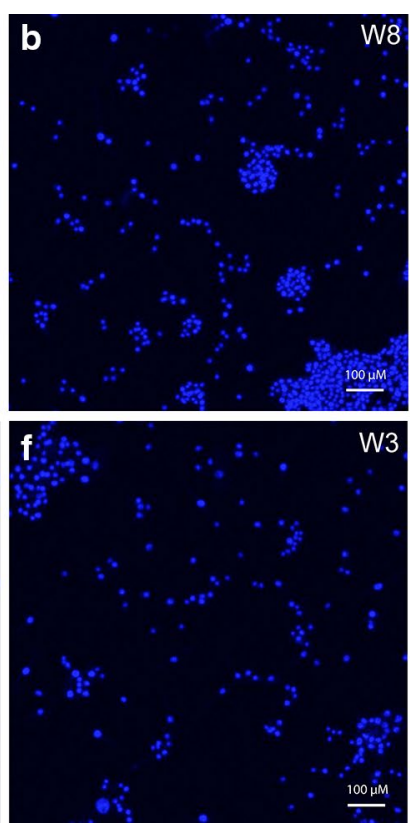
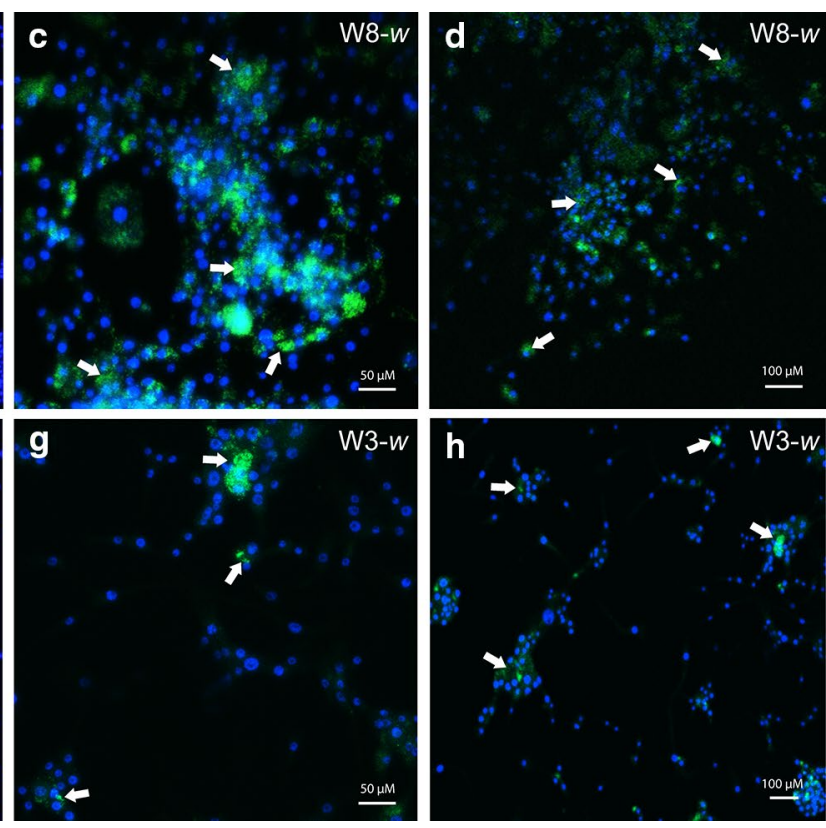

Fig. 2 Fluorescent in situ hybridization of uninfected $(\mathbf{a}, \mathbf{b})$ and Wolbachia-infected W8-w cells (c, d) at $60 \times$ and $20 \times$ magnifications, respectively. FISH of uninfected $(\mathbf{e}, \mathbf{f})$ and Wolbachia-infected W3-W cells $(\mathbf{g}, \mathbf{h})$ at $60 \times$ and $20 \times$ magnifications, respectively. Cell nuclei are shown in blue and Wolbachia specific probes are shown in green. White arrows indicate the presence of Wolbachia in cells 
low level of infection in the W3- $w$ cell lines, while FISH in the w8- $w$ cell line suggested a higher density infection compared to W3-w (Fig. 2).

\section{Wolbachia effects on immune gene expression in Wolbachia infected Culicoides cells}

After the establishment of a Wolbachia infection in the W3- $w$ and W8- $w$ cell lines at passage 5, we examined the gene expression of immune response in only the W8- $w$ cell line due to the higher density of the walbB infection. To examine for an interaction of $w$ albB and the host cell immune response, we performed qPCR on selected genes in the JAK-STAT, IMD and Toll pathways. In addition, we examined the expression of other immune-related genes including antimicrobial peptides
(AMPs). W8- $w$ infected cells had a significant increase in immune gene expression for STAT (t-test; $t=4.14$, $d f=3, P=0.01$ ), PIAS (t-test; $t=3.18, d f=3, P=0.02$ ), Caspar (t-test; $t=3.22, d f=3, P=0.04$ ), Relish (t-test; $t=2.02, d f=3, P=0.05)$, Dorsal (t-test; $t=3.01, d f=3$, $\mathrm{P}=0.02)$, Cactus (t-test; $t=3.04, \quad d f=3, \quad P=0.03$ ), Attacin (t-test; $t=3.16, d f=3, P=0.03$ ) and Attacinlike genes (t-test; $t=2.81, d f=3, P=0.05)$ when compared to W8 uninfected cells (Fig. 3). Cercropin (t-test; $t=0.05, d f=3, P=0.48)$, Defensin (t-test; $t=0.66$, $d f=4, \quad P=0.27$ ) and Defensin-like (t-test, $t=2.32$, $d f=4, P=0.06)$ showed no significant difference in immune gene expression when compared to the uninfected W8 cells (Fig. 3).

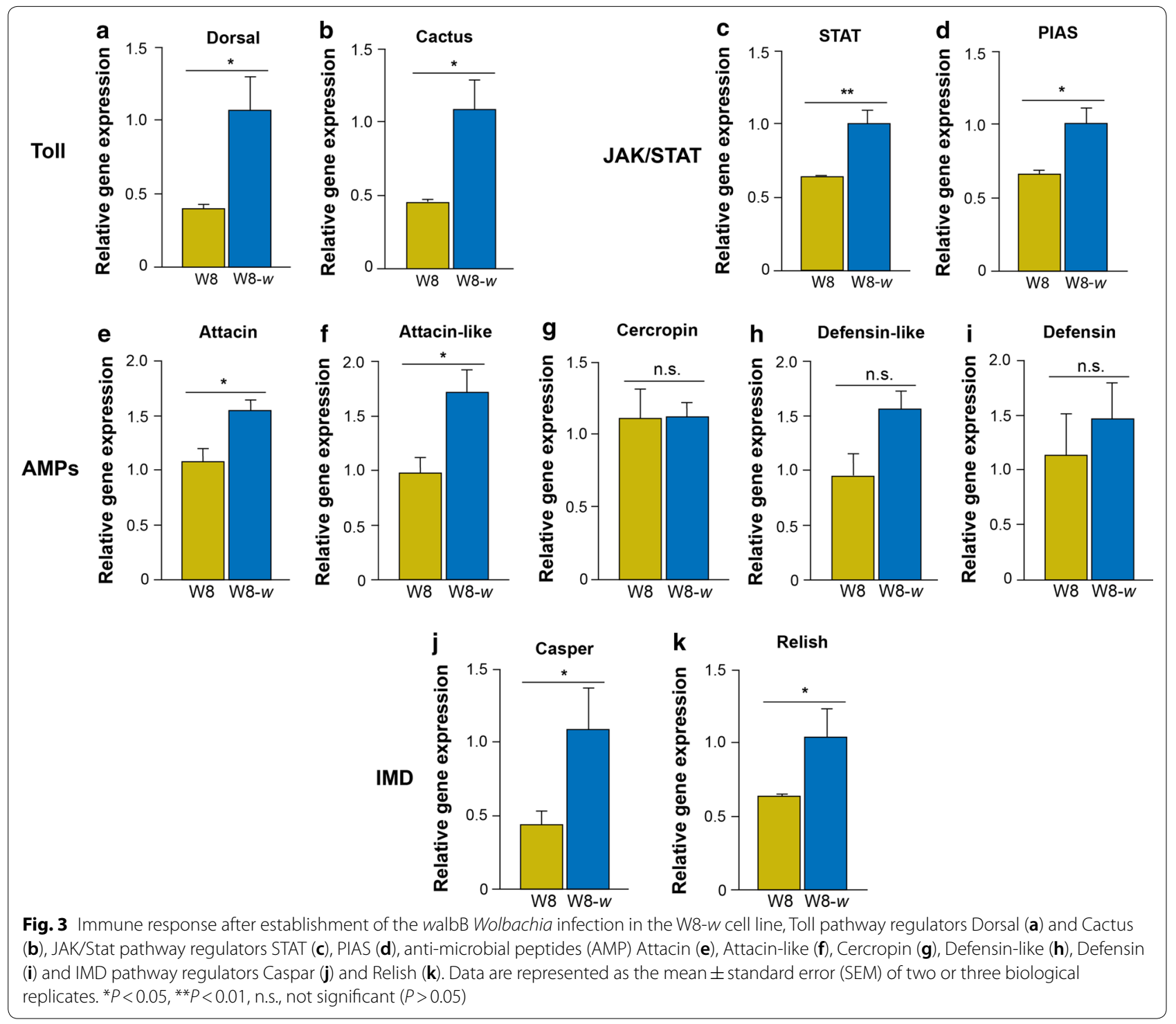




\section{Discussion}

The generation of cell lines with novel Wolbachia infections is a logical first step towards investigating whether an infection can be established in a novel insect host. Transfer of Wolbachia to novel hosts is time consuming and difficult using microinjection techniques to introduce Wolbachia infections into insect embryos, and more often than not, attempts are met with limited success. Wolbachia establishment in cell lines has also been shown as a way to pre-adapt a Wolbachia infection to a novel host potentially leading to a more successful transfection $[35,38]$. The generation of two novel Wolbachia-infected C. sonorensis cell lines (W8$w$ and $\mathrm{W} 3-w)$ is a notable advancement towards generating novel Wolbachia infections in adult midges.

The observed Wolbachia infection densities in the W8- $w$ and W3- $w$ cell lines are lower than previously reported for Drosophila, mosquito and sand fly host cells [35, 43, 44]. While higher Wolbachia infection densities have been reported to result in pathogen blocking and cytoplasmic incompatibility $[41,45,46]$, other studies have suggested that low level infections can also result in cytoplasmic incompatibility (CI) and possibly pathogen blocking [47, 48]. Few studies have examined for Wolbachia infections in native Culicoides spp. populations, and those that have, demonstrated that Culicoides species have low density Wolbachia infections in vivo and a low prevalence in natural populations [33, 34]. Detection of Wolbachia infections in Culicoides spp. collected in Australia was accomplished by using GPCR over less sensitive conventional PCR [33]. Wolbachia infections have also been noted in Culicoides spp. collected in Spain, albeit at a low prevalence in populations, which could again be associated with a low Wolbachia density in adult host midges and a low detection level [34]. Hence, the low densities of Wolbachia observed in the W8-w and W3-w cell lines may be common to Culicoides. This observed result could be a function of the ability of Wolbachia to upregulate the immune system in its Culicoides host and inhibiting Wolbachia infection proliferation, or could be the result of environmental parameters such as temperature [49-51], host age [50, 52], sex [52] or Wolbachia strain [53], which have been demonstrated to impact Wolbachia density in its insect host. It is currently unclear why the W8-w cell line is able to maintain a higher Wolbachia density than the W3-w cell line, but this observation could be related to predominant cell morphology and type of each culture. The W3 cell line is predominantly, epithelial-like cells that are firmly adherent [38]. The W8 cell line contains predominantly fusiform or stellate shaped cells, which are lightly adherent [38]. Previous studies have shown Wolbachia can infect multiple cell and tissue types at different rates and densities [54].

The W8- $w$ and W3-w cell lines were infected with a walbB infection from donor Aa23 Ae. albopictus cells. The walbB infection type was an optimal candidate for C. sonorensis cell line transfection because: (i) the walbB infection has been shown to fall within the same B-clade as other Wolbachia infections reported in multiple Culicoides spp. collected in native populations in Spain [34], suggesting a higher likelihood for a successful transfection; and (ii) the $w$ AlbB infection has shown parasite and virus inhibitory effects in multiple insect vectors of disease. In Anopheles stephensi, walbB has been demonstrated to reduce Plasmodium parasite development [55, 56]. Also, walbB has been demonstrated to suppress filarial worm loads and provide resistance to dengue virus transmission in Aedes polynesiensis [57].

While parasite and pathogen inhibitory effects have been reported in multiple Wolbachia insect systems, the mechanism of pathogen inhibition in Wolbachia infected insect hosts is not well understood [58-60]. Currently, there are two hypotheses proposed to understand Wolbachia induced pathogen inhibition. The first is that Wolbachia primes the host immune system, so when the pathogen enters the insect host, invasion is inhibited. Second, Wolbachia is hypothesized to be competing for metabolic components such as amino acids and cholesterol with the host insect and the pathogen [61, 62]. For example, Wolbachia replication is known to be dependent upon host cell cholesterol production and requires cholesterol-rich host membranes to form the vacuole surrounding each bacterium, which is hypothesized to lead to competition for cholesterol between Wolbachia and pathogens $[61,63]$. To test the first hypothesis, we examined the expression of immune related genes in the IMD, Toll and JAk/STAT pathways in the W8- $w$ cell line. Unfortunately, knowledge of immune pathways in C. sonorensis is limited, but several immune genes have been identified and characterized in a previous study [64]. Furthermore, the availability of the C. sonorensis annotated genome (GenBank: GCA_900258525) allowed for the identification of genes in Toll, JAK/STAT and IMD pathways [65]. The upregulation of Dorsal, Cactus, STAT, PIAS, Caspar, RELISH, Attacin, and an Attacinlike anti-microbial peptides suggest that Wolbachia can affect the $C$. sonorensis immune system pathways in different cascades. Perhaps, this priming of the immune system could have an effect on orbivirus proliferation in its Culicoides host. Previous transcriptome studies have demonstrated 165 genes, including genes in the Toll and IMD pathways and AMPs that were differentially expressed between vector competent or refractory $C$. 
sonorensis when challenged with a BTV infection [65]. Future studies could include the inoculation of W8- $w$ and W3- $w$ cell lines with the orbiviruses BTV, AHSV, SBV, and/or EHDV and determining whether a novel Wolbachia infection can induce virus inhibitory effect in $C$. sonorensis cells. Both the W3 and W8 cell lines have previously been shown to be susceptible to BTV and EHDV infection [38]. If pathogen viral inhibition is observed, additional gene families other than traditional gene pathways could also be investigated for their functional role in potential pathogen blocking [66].

Here we have only examined the effect of one Wolbachia infection type on $C$. sonorensis cells. Future studies could also include the transfection of W8 and W3 cell lines with alternative Wolbachia infections such as $w \mathrm{Mel}$, which has also been demonstrated to provide virus inhibitory phenotypes in mosquitoes [46, 67]. It is also important to note that while the data presented suggest an upregulation in the immune system and a potential pathogen blocking effect, there is the possibility that a Wolbachia and Culicoides host association facilitates a pathogen infection in Culicoides spp. Previous studies have demonstrated an increase in the ability of Culex tarsalis to transmit West Nile virus when infected with Wolbachia and an enhanced flavivirus infection rate in Ae. aegypti $[68,69]$.

The W8- $w$ and W3- $w$ cell lines will continue to be passaged and maintained, with the goal of adapting the walbB infection to C. sonorensis. Subsequently, the walbB Culicoides adapted infection can be extracted from the W8-w or W3-w cell line and used for future microinjection experiments with the goal of generating a $w$ albB germ line infection in $C$. sonorensis adults. If a stable germ line maternally inherited Wolbachia infection can be attained in C. sonorensis adults, further work would be needed to ascertain whether novel Wolbachia infections have an effect on $C$. sonorensis fitness, any reproductive phenotypes such as CI associated with Wolbachia infections, or any orbiviruses inhibitory effects. Further investigation is also needed to develop microinjection protocols for introducing Wolbachia infections into $C$. sonorensis embryos. This future work would open up exciting possibilities to investigate whether Wolbachiabased approaches could be used as an additional tool to control C. sonorensis and other Culicoides species and as an additional tool to limit transmission of veterinary important orbiviruses.

\section{Conclusions}

Here, we were able to establish a Wolbachia infection in C. sonorensis cells (W8 and W3 cell lines) and that the W8 Wolbachia infected cell line demonstrated an upregulation of the Toll, IMD, JACK/STAT pathways and the production of anti-microbial peptides. The results suggest the potential utility of Wolbachia-based approaches for vector control strategies and to limit disease transmission by C. sonorensis and other Culicoides species of veterinary importance. Further investigation is needed to introduce germline infections into C. sonorensis and examine for Wolbachia induced reproductive phenotypes and pathogen inhibitory effects.

\section{Supplementary information}

Supplementary information accompanies this paper at https://doi. org/10.1186/s13071-019-3716-0.

Additional file 1: Table S1. Primer sequences used to confirm Wolbachia infection status, determine Wolbachia density, and host immune pathway gene expression.

\section{Abbreviations}

AHSV: African horse sickness virus; SBV: Schmallenberg virus; BTV: bluetongue virus; EHDV: epizootic hemorrhagic disease virus; Cl: cytoplasmic incompatibility; IIT: incompatible insect technique; AMP: anti-microbial peptides; SM: Schneider's media; FBS: fetal bovine serum; FISH: fluorescent in situ hybridization; PCR: polymerase chain reaction; qPCR: quantitative polymerase chain reaction; DTT: dithriothreitol; SCC: sodium saline citrate; RT: room temperature: PBS: phosphate-buffered saline; PBS-T: phosphate-buffered saline-Tween.

\section{Acknowledgements}

We would like to thank Dr. Peter Keyel for his helpful advice concerning microscopy and the College of Arts \& Sciences Microscopy Texas Tech University (Lubbock, TX, USA) for use of their facilities. We would also like to thank Phillip Shults for his helpful advice on C. sonorensis ecology and biology and Zhiyong Xi for providing Aa23 cells.

\section{Authors' contributions}

CLB and $A G$ conceived and designed the experiments. AG performed the experiments. CLB and $A G$ analyzed the data. CLB, AG, DJ and $L C$ wrote the paper. DJ and LC provided C. sonoresnsis cell lines for experiments. All authors read and approved the final manuscript.

\section{Funding}

This work was supported by Texas Tech University start-up funds.

\section{Availability of data and materials}

The Culicoides cell cultures that support the findings of this study are available from the United States Department of Agriculture Agricultural Research Service Arthropod-borne Animal Diseases Research Unit, but restrictions apply to the availability of these cultures, which were used under license for the current study, and so are not publicly available. Data are however available from the authors upon reasonable request and with permission of Department of Agriculture Agricultural Research Service Arthropod-borne Animal Diseases Research Unit.

\section{Ethics approval and consent to participate}

Not applicable.

\section{Consent for publication}

Not applicable.

\section{Competing interests}

The authors declare that they have no competing interests.

\section{Author details}

${ }^{1}$ Department of Biological Sciences, Texas Tech University, 2901 Main St., Lubbock, TX 79409, USA. ${ }^{2}$ USDA-ARS Arthropod Borne Animal Disease Research Unit, 1515 College Ave., Manhattan, KS 66502, USA. 
Received: 19 June 2019 Accepted: 14 September 2019

Published online: 15 October 2019

\section{References}

1. Mills MK, Michel K, Pfannenstiel RS, Ruder MG, Veronesi E, Nayduch D. Culicoides-virus interactions: infection barriers and possible factors underlying vector competence. Curr Opin Insect Sci. 2017;22:7-15.

2. Pfannenstiel RS, Mullens BA, Ruder MG, Zurek L, Cohnstaedt LW, Nayduch D. Management of North American Culicoides biting midges: current knowledge and research needs. Vector Borne Zoonotic Dis. 2015;15:374-84

3. De Clercq K, Mertens P, De Leeuw I, Oura C, Houdart P, Potgieter AC, et al. Emergence of bluetongue serotypes in Europe, part 2: the occurrence of a BTV-11 strain in Belgium. Transbound Emerg Dis. 2009;56:355-61.

4. Vandenbussche F, De Leeuw I, Vandemeulebroucke E, De Clercq K. Emergence of bluetongue serotypes in Europe, part 1: description and validation of four real-time RT-PCR assays for the serotyping of bluetongue viruses BTV-1, BTV-6, BTV-8 and BTV-11. Transbound Emerg Dis. 2009;56:346-54

5. Velthuis AG, Saatkamp HW, Mourits MC, de Koeijer AA, Elbers AR. Financial consequences of the Dutch bluetongue serotype 8 epidemics of 2006 and 2007. Prev Vet Med. 2010;93:294-304.

6. Ostlund E. Report of the committee on bluetongue and bovine retroviruses. In: Proceedings of the Annual Meeting of the US Animal Health Association. Saint Joseph: United States Animal Health Association; 2011. p. 163-64.

7. Ostlund E. Report of the committee on bluetongue and bovine retroviruses. In: Proceedings of the Annual Meeting of the US Animal Health Association. Saint Joseph: United States Animal Health Association; 2012. p. 191-92.

8. Ostlund E. Report of the committee on bluetongue and bovine retroviruses. In: Proceedings of the Annual Meeting of the US Animal Health Association. Saint Joseph: United States Animal Health Association; 2013. p. 143-46.

9. Ostlund E. Report of the committee on bluetongue and bovine retroviruses. In: Proceedings of the Annual Meeting of the US Animal Health Association. Saint Joseph: United States Animal Health Association; 2014. p. 157-62.

10. Ostlund E. Report of the committee on bluetongue and bovine retroviruses. In: Proceedings of the Annual Meeting of the US Animal Health Association. Saint Joseph: United States Animal Health Association; 2015. p. 112-16.

11. Gibbs EP, Tabachnick WJ, Holt TJ, Stallknecht DE. U.S. concerns over bluetongue. Science. 2008;320:872.

12. Hasler B, Howe KS, Di Labio E, Schwermer H, Stark KD. Economic evaluation of the surveillance and intervention programme for bluetongue virus serotype 8 in Switzerland. Prev Vet Med. 2012;103:93-111.

13. Mullens BA, McDermott EG, Gerry AC. Progress and knowledge gaps in Culicoides ecology and control. Vet Ital. 2015;51:313-23.

14. Benelli G, Buttazzoni L, Canale A, D’Andrea A, Del Serrone P, Delrio G, et al. Bluetongue outbreaks: looking for effective control strategies against Culicoides vectors. Res Vet Sci. 2017;115:263-70.

15. Bandeira M, Brito GA, da Penha A, Santos CLC, Rebelo JMM. The influence of environmental management and animal shelters in vector control of Culicoides (Diptera, Ceratopogonidae) in northeastern Brazil. J Vector Ecol. 2017:42:113-9.

16. Carpenter S, Mellor PS, Torr SJ. Control techniques for Culicoides biting midges and their application in the U.K. and northwestern Palaearctic. Med Vet Entomol. 2008;22:175-87.

17. Orbiviruses, bluetongue and epizootic hemmorhagic disease: gap analysis workshop report. Washington, DC.: U.S. Department of Agriculture, Agricultural Research Service; 2013.

18. Ruder MG, LysykTJ, Stallknecht DE, Foil LD, Johnson DJ, Chase CC, et al. Transmission and epidemiology of bluetongue and epizootic hemorrhagic disease in North America: current perspectives, research gaps, and future directions. Vector Borne Zoonotic Dis. 2015;15:348-63.

19. Ranjan K, Prasad M, Brar B, Lambe U, Kumar R, Ghosh M, et al. Bluetongue virus vaccine: conventional to modern approach. Acta Virol. 2019;63:3-18.
20. Mayo C, Lee J, Kopanke J, MacLachlan NJ. A review of potential bluetongue virus vaccine strategies. Vet Microbiol. 2017;206:84-90.

21. Werren JH, Windsor DM. Wolbachia infection frequencies in insects: evidence of a global equilibrium? Proc Biol Sci. 2000;267:1277-85.

22. Hilgenboecker K, Hammerstein P, Schlattmann P, Telschow A, Werren JH. How many species are infected with Wolbachia? - a statistical analysis of current data. FEMS Microbiol Lett. 2008;281:215-20.

23. Werren JH, Baldo L, Clark ME. Wolbachia: master manipulators of invertebrate biology. Nat Rev Microbiol. 2008;6:741-51.

24. Rosenberg R, Lindsey N, Fischer M. Vital signs: trends in reported vectorborne disease cases_-United States and territories, 2004-2016. Morb Mortality Wkly Rep (MMWR). 2018;67:496-501.

25. Brelsfoard CL, Dobson SL. Wolbachia-based strategies to control insect pests and disease vectors. Asia Pac J Mol Biol. 2009;17:55-63.

26. Mains JW, Brelsfoard CL, Rose RI, Dobson SL. Female adult Aedes albopictus suppression by Wolbachia-infected male mosquitoes. Sci Rep. 2016;6:33846.

27. O'Connor L, Plichart C, Sang AC, Brelsfoard CL, Bossin HC, Dobson SL. Open release of male mosquitoes infected with a Wolbachia biopesticide: field performance and infection containment. PLoS Negl Trop Dis. 2012;6:e1797.

28. Moreira LA, Iturbe-Ormaetxe I, Jeffery JA, Lu G, Pyke AT, Hedges LM, et al. A Wolbachia symbiont in Aedes aegypti limits infection with dengue, chikungunya, and Plasmodium. Cell. 2009;139:1268-78.

29. van den Hurk AF, Hall-Mendelin S, Pyke AT, Frentiu FD, McElroy K, Day A, et al. Impact of Wolbachia on infection with chikungunya and yellow fever viruses in the mosquito vector Aedes aegypti. PLoS Negl Trop Dis. 2012;6:e1892.

30. Caragata EP, Dutra HL, Moreira LA. Inhibition of Zika virus by Wolbachia in Aedes aegypti. Microb Cell. 2016;3:293-5.

31. Tan CH, Wong PJ, Li MI, Yang H, Ng LC, Oeill SL. WMel limits Zika and chikungunya virus infection in a Singapore Wolbachia-introgressed Ae. aegypti strain, wMel-Sg. PLoS Negl Trop Dis. 2017;11:e0005496.

32. Flores HA, O'Neill SL. Controlling vector-borne diseases by releasing modified mosquitoes. Nat Rev Microbiol. 2018;16:508-18.

33. Mee PT, Weeks AR, Walker PJ, Hoffmann AA, Duchemin JB. Detection of low-level Cardinium and Wolbachia infections in Culicoides. Appl Environ Microb. 2015:81:6177-88.

34. Pages N, Munoz-Munoz F, Verdun M, Pujol N, Talavera S. First detection of Wolbachia-infected Culicoides (Diptera: Ceratopogonidae) in Europe: Wolbachia and Cardinium infection across Culicoides communities revealed in Spain. Parasit Vectors. 2017;10:582.

35. McMeniman CJ, Lane AM, Fong AW, Voronin DA, Iturbe-Ormaetxe I, Yamada R, et al. Host adaptation of a Wolbachia strain after longterm serial passage in mosquito cell lines. Appl Env Microbiol. 2008;74:6963-9.

36. Dobson SL, Marsland EJ, Veneti Z, Bourtzis K, O'Neill SL. Characterization of Wolbachia host cell range via the in vitro establishment of infections. Appl Environ Microbiol. 2002;68:656-60.

37. Rasgon JL, Gamston CE, Xiaoxia R. Survival of Wolbachia pipientis in cell-free medium. Appl Env Microbiol. 2006;72:6934-7.

38. McHolland LE, Mecham JO. Characterization of cell lines developed from field populations of Culicoides sonorensis (Diptera: Ceratopogonidae). J Med Entomol. 2003;40:348-51.

39. Ahantarig A, Trinachartvanit W, Kittayapong P. Relative Wolbachia density of field-collected Aedes albopictus mosquitoes in Thailand. J Vector Ecol. 2008;33:173-7.

40. Frentiu FD, Robinson J, Young PR, McGraw EA, O'Neill SL. Wolbachiamediated resistance to dengue virus infection and death at the cellular level. PLoS ONE. 2010;5:e13398.

41. Lu P, Bian G, Pan X, Xi Z. Wolbachia induces density-dependent inhibition to dengue virus in mosquito cells. PLoS Negl Trop Dis. 2012;6:e1754.

42. Sheehan KB, Martin M, Lesser CF, Isberg RR, Newton IL. Identification and characterization of a candidate Wolbachia pipientis type IV effector that interacts with the actin cytoskeleton. MBio. 2016;7:e00622.

43. da Silva Goncalves D, Iturbe-Ormaetxe I, Martins-da-Silva A, Telleria EL, Rocha MN, Traub-Cseko YM, et al. Wolbachia introduction into Lutzomyia longipalpis (Diptera: Psychodidae) cell lines and its effects on immunerelated gene expression and interaction with Leishmania infantum. Parasit Vectors. 2019:12:33. 
44. Voronin D, Tran-Van V, Potier P, Mavingui P. Transinfection and growth discrepancy of Drosophila Wolbachia strain WMel in cell lines of the mosquito Aedes albopictus. J Appl Microbiol. 2010;108:2133-41.

45. Bian G, Xu Y, Lu P, Xie Y, Xi Z. The enosymbiotic bacterium Wolbachia induces resistance to dengue virus in Aedes aegypti. PLoS Pathog. 2010;6:e1000833.

46. Hoffmann AA, Ross PA, Rasic G. Wolbachia strains for disease control: ecological and evolutionary considerations. Evol Appl. 2015;8:751-68.

47. Richardson KM, Griffin PC, Lee SF, Ross PA, Endersby-Harshman NM, Schiffer M, et al. A Wolbachia infection from Drosophila that causes cytoplasmic incompatibility despite low prevalence and densities in males. Heredity. 2019;122:428-40.

48. Monsanto-Hearne V, Johnson KN. Wolbachia-mediated protection of Drosophila melanogaster against systemic infection with its natural viral pathogen Drosophila C virus does not involve changes in levels of highly abundant miRNAs. J Gen Virol. 2018;99:827-31.

49. Hurst GD, Johnson AP, Schulenburg JH, Fuyama Y. Male-killing Wolbachia in Drosophila: a temperature-sensitive trait with a threshold bacterial density. Genetics. 2000;156:699-709.

50. Reynolds KT, Thomson $\sqcup$, Hoffmann AA. The effects of host age, host nuclear background and temperature on phenotypic effects of the virulent Wolbachia strain popcorn in Drosophila melanogaster. Genetics. 2003;164:1027-34.

51. Wiwatanaratanabutr I, Kittayapong P. Effects of crowding and temperature on Wolbachia infection density among life cycle stages of Aedes albopictus. J Invertebr Pathol. 2009;102:220-4.

52. Tortosa P, Charlat S, Labbe P, Dehecq JS, Barre H, Weill M. Wolbachia agesex-specific density in Aedes albopictus: a host evolutionary response to cytoplasmic incompatibility? PLoS ONE. 2010;5:e9700.

53. Dutton TJ, Sinkins SP. Strain-specific quantification of Wolbachia density in Aedes albopictus and effects of larval rearing conditions. Insect Mol Biol. 2004;13:317-22

54. Pietri JE, DeBruhl H, Sullivan W. The rich somatic life of Wolbachia. Microbiologyopen. 2016:5:923-36.

55. Bian G, Joshi D, Dong Y, Lu P, Zhou G, Pan X, et al. Wolbachia invades Anopheles stephensi populations and induces refractoriness to Plasmodium infection. Science. 2013;340:748-51.

56. Joshi D, Pan X, McFadden MJ, Bevins D, Liang X, Lu P, et al. The maternally inheritable Wolbachia wAlbB induces refractoriness to Plasmodium berghei in Anopheles stephensi. Front Microbiol. 2017;8:366.

57. Bian G, Zhou G, Lu P, Xi Z. Replacing a native Wolbachia with a novel strain results in an increase in endosymbiont load and resistance to dengue virus in a mosquito vector. PLoS Negl Trop Dis. 2013;7:e2250.
58. Osborne SE, Leong YS, O'Neill SL, Johnson KN. Variation in antiviral protection mediated by different Wolbachia strains in Drosophila simulans. PLoS Pathog. 2009;5:e1000656.

59. Rainey SM, Shah P, Kohl A, Dietrich I. Understanding the Wolbachia-mediated inhibition of arboviruses in mosquitoes: progress and challenges. J Gen Virol. 2014;95:517-30

60. Terradas G, McGraw EA. Wolbachia-mediated virus blocking in the mosquito vector Aedes aegypti. Curr Opin Insect Sci. 2017;22:37-44.

61. Caragata EP, Rances E, Hedges LM, Gofton AW, Johnson KN, O’Neill SL et al. Dietary cholesterol modulates pathogen blocking by Wolbachia. PLoS Pathog. 2013;9:e1003459.

62. Caragata EP, Rances E, O'Neill SL, McGraw EA. Competition for amino acids between Wolbachia and the mosquito host, Aedes aegypti. Microb Ecol. 2014;67:205-18.

63. Atella GC, Bittencourt-Cunha PR, Nunes RD, Shahabuddin M, Silva-Neto MA. The major insect lipoprotein is a lipid source to mosquito stages of malaria parasite. Acta Trop. 2009;109:159-62.

64. Nayduch D, Lee MB, Saski CA. Gene discovery and differential expression analysis of humoral immune response elements in female Culicoides sonorensis (Diptera: Ceratopogonidae). Parasit Vectors. 2014;7:388.

65. Morales-Hojas R, Hinsley M, Armean IM, Silk R, Harrup LE, Gonzalez-Uriarte A, et al. The genome of the biting midge Culicoides sonorensis and gene expression analyses of vector competence for bluetongue virus. BMC Genomics. 2018;19:624.

66. Sigle LT, McGraw EA. Expanding the canon: non-classical mosquito genes at the interface of arboviral infection. Insect Biochem Mol Biol. 2019;109:72-80.

67. Walker T, Johnson PH, Moreira LA, Iturbe-Ormaetxe I, Frentiu FD, McMeniman CJ, et al. The wMel Wolbachia strain blocks dengue and invades caged Aedes aegypti populations. Nature. 2011:476:450-3.

68. Amuzu HE, Tsyganov K, Koh C, Herbert RI, Powell DR, McGraw EA. Wolbachia enhances insect-specific flavivirus infection in Aedes aegypti mosquitoes. Ecol Evol. 2018;8:5441-54.

69. Dodson BL, Hughes GL, Paul O, Matacchiero AC, Kramer LD, Rasgon JL. Wolbachia enhances West Nile virus (WNV) infection in the mosquito Culex tarsalis. PLoS Negl Trop Dis. 2014;8:e2965.

\section{Publisher's Note}

Springer Nature remains neutral with regard to jurisdictional claims in published maps and institutional affiliations.
Ready to submit your research? Choose BMC and benefit from:

- fast, convenient online submission

- thorough peer review by experienced researchers in your field

- rapid publication on acceptance

- support for research data, including large and complex data types

- gold Open Access which fosters wider collaboration and increased citations

- maximum visibility for your research: over $100 \mathrm{M}$ website views per year

At BMC, research is always in progress.

Learn more biomedcentral.com/submissions 